\title{
DNA origami inside-out viruses
}

Jonathan R. Burns, ${ }^{1,2}$ Baptiste Lamarre, ${ }^{1}$ Alice L. B. Pyne, ${ }^{3}$ James E. Noble ${ }^{1}$ and Maxim G.

$$
\text { Ryadnov }^{1 *}
$$

${ }^{1}$ National Physical Laboratory, Hampton Road, Teddington, TW11 0LW, UK

${ }^{2}$ Department of Chemistry, University College London, London, WC1E 6BT, UK

${ }^{3}$ London Centre for Nanotechnology, University College London, London, WC1E 6BT, UK

Corresponding author:

Dr Maxim G Ryadnov

National Physical Laboratory,

Hampton Road, Teddington, TW11 0LW, UK

Fax: (+44) 2086140573

Tel: (+44) 2089436078

max.ryadnov@npl.co.uk 
ABSTRACT: A synthetic topology for everted viruses is reported. The topology is a singlestranded virion DNA assembled into a hollow cube with exterior decorated with HIV-Tat transduction domains. The cube incorporates a pH-responsive lid allowing for the controlled encapsulation of functional proteins and their transfer and release into live cells. Unlike viruses, which are protein shells with a [3, 5]-fold rotational symmetry that encase nucleic acids, these cubes are $[3,4]$-fold DNA boxes encapsulating proteins. Like viruses, such everted DNA-built viruses are monodisperse nanoscale assemblies that infect human cells with a specialist cargo. The design offers a bespoke bottom-up platform for engineering non-polyhedral, non-protein synthetic viruses.

Keywords: synthetic viruses, DNA origami, green fluorescent protein, transfection, microscopy

Viruses can be viewed as hollow boxes encapsulating nucleic acids. ${ }^{1}$ They assemble from proteins into spherical or filamentous nanoscale shells with an $n$-fold rotational symmetry, where $n$ can be 3 or 5 or both, and are said to have a [3, 5]-fold symmetry topology. ${ }^{2}$ Such a relatively strict requirement for symmetry underpins the phenomenal reproducibility of viruses, which is ensured by the ability of proteins to fold into globular structures. As comparatively straightforward assemblies all viruses deliver the same function - gene expression. When combined with the efficacy with which viruses infect cells this property inspires the search for artificial analogues. ${ }^{3}$ Different chemistries and approaches are being explored, though little emphasis is placed on the structural cooperativity of viruses. ${ }^{4-9}$ Encouragingly, most recent synthetic designs reach the uniformity of viral particles, ${ }^{10-12}$ with emerging examples demonstrating effective gene silencing and expression. ${ }^{12,13}$ An ultimate objective of virus-like systems is to enable the intracellular synthesis or delivery of a target protein. Viruses are not natural vehicles for protein delivery and therefore require an auxiliary means for encapsulation. 
Covalent fusion with capsid proteins or the introduction of non-specific tags are among common methods used. ${ }^{14-16}$ Engineered protein boxes face similar issues, while their functional fitness strictly depends on the programmability of assembly, which remains inferior to that of native viruses. ${ }^{17}$ An alternative can be provided by a molecular class demonstrating a superior (or better understood) programmability that is intrinsically compatible with non-covalent protein encapsulation. A strategy to realize this is to evert the gene delivery of protein-built boxes into the protein delivery of DNA-built boxes - the concept that we introduce herein as an inside-out or everted virus topology.

\section{Results and Discussion}

The topology adapts the principles of DNA origami using the M13mp18 genomic DNA as a scaffold strand. ${ }^{18}$ Since their inception the principles prove versatile for programming DNA forms of virtually any complexity, ${ }^{19,20}$ while interest in intracellular applications has been steadily increasing. ${ }^{20-22}$ As DNA does not typically traverse cellular membranes, origami structures are being attempted as conjugates with proteins targeting cellular receptors, ${ }^{23,24}$ complexes with hydrophobic drugs ${ }^{25}$ or as cargo in viruses ${ }^{26}$ and lipid envelops. ${ }^{27}$ Unlike linear or plasmid DNA, 3D-folded origami constructs such as icosahedral cages may be used to host fluorescent cargo for in vivo imaging, ${ }^{28}$ intercalate anticancer drugs for cancer targeting, ${ }^{29}$ enable light-triggered release of bioactives ${ }^{30}$ or geometrically adapt to tailor protein encapsulation. ${ }^{31}$ The delivery of folded proteins is an altogether different proposition entailing the challenges of controlled and functional delivery, which may not be achieved using structures as fixed and porous as icosahedral cages. For these reasons, we chose the topology of a three-dimensional cube, in which one face serves as a lid (Table S1 and Fig S1 in Supporting Information).

The design is an equilateral 25-nm hollow box with characteristic 2-, 3- and 4-fold symmetries, which renders it a [3, 4]-fold symmetry topology (Fig 1A \& S2). The cube is held together by 
single-strand staples that lock lid and bottom faces orthogonally via one side (Table S1, Fig S1-S3). ${ }^{32}$ The lid side is hinged on short i-motif staples that undergo conformational transition in response to lowered $\mathrm{pH}$ (from neutral), inducing the opening of the box (Table S2, Fig 1A \& S2). Thus, unlike other locking systems including DNA lock-key clasps ${ }^{33}$ and aptamerencoded logic gates,${ }^{34}$ this design does not require externally applied keys. Instead, the hinge regions switch conformations within a narrow $\mathrm{pH}$ range as a sufficient means to respond to acidic endosomal environments thereby facilitating the egress of encapsulated cargo (Fig 1A).
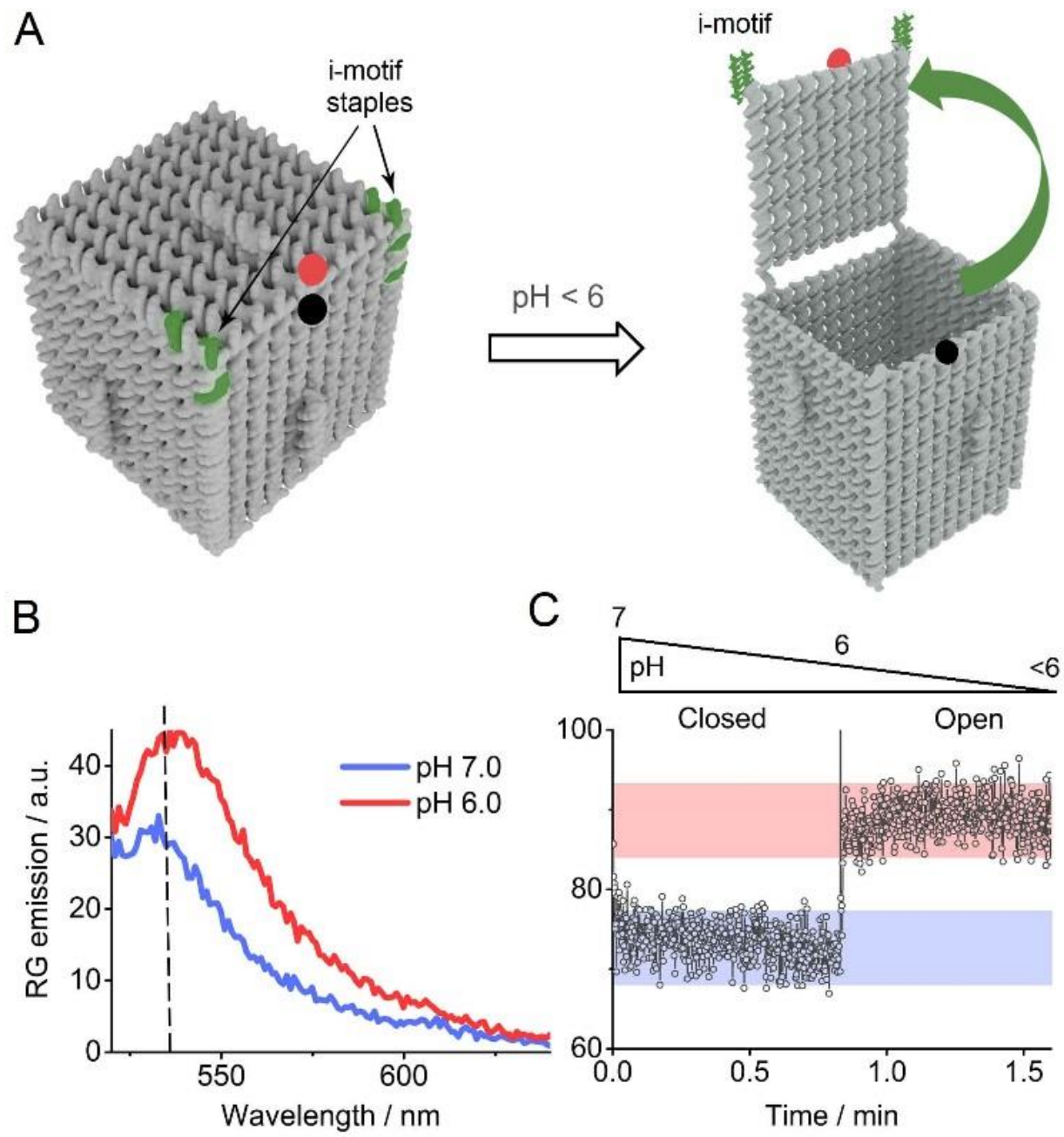

Figure 1. A [3, 4]-fold DNA topology with controllable lid opening. (A) 3D models of an assembled DNA box (grey) locked with i-motif staples (green), which upon lowering pH undergo conformational transition resulting in lid opening (green arrow). Reporter (rhodamine G, RG) and quencher (dabcyl) are shown in red and black, respectively. (B) RG emissions at $535 \mathrm{~nm}$ corresponding to closed (pH 7) and open (pH 6) states in FRET spectra (B) and plotted versus time (C). 
As gauged by electrophoretic and chromatographic measurements, the topology yielded a monodisperse assembly (Fig S4). Further, circular dichroism (CD) absorption spectra revealed characteristic signal enhancements at $285 \mathrm{~nm}$ (B-form DNA) for individual i-motif strands with decreasing $\mathrm{pH}$ (Fig S5A). These findings indicate a stabilized i-motif formation at $\mathrm{pH}<6,{ }^{35}$ and are in accord with electrophoretic measurements that revealed the disintegration of the assembly down to the scaffold strand at $\mathrm{pH}<5.6$ (Fig S5B). To monitor the lid opening, fluorescence resonance energy transfer (FRET) was measured using a pH-independent reporter-quencher pair incorporated into the lid (rhodamine $\mathrm{G}$ - reporter) and the lock face of the box (dabcyl - quencher) (Table S3, Fig S2 \& 1B). The pair was chosen because the fluorescence yield of RG is insensitive to changes in $\mathrm{pH} 4.0-9.0 .^{36}$ Therefore, the fluorescence of the pair depends exclusively on whether the box is open (RG is away from dabcyl) or closed (RG and dabcyl are nearby).
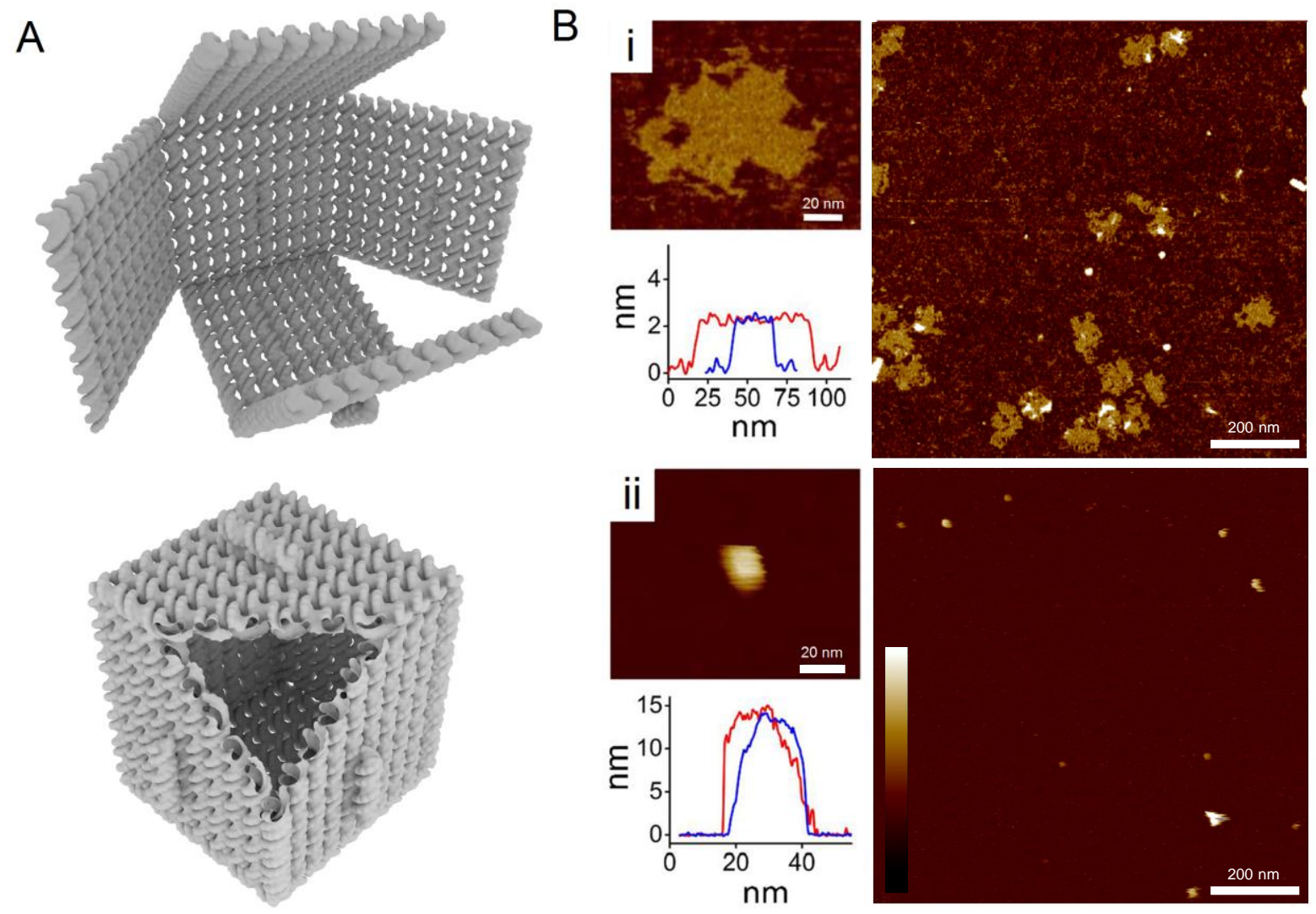

Figure 2. A [3, 4]-fold DNA assembly. (A) 3D molecular models of a DNA origami box in a prefolded (upper) and a fully assembled, closed, (lower) states. (B) AFM topography images obtained at 
neutral $\mathrm{pH}$ for pre-folded (i) and closed (ii) states, with corresponding cross-sections across the individual boxes. Colour scale bars (height) are $8 \mathrm{~nm}$ for (i) and $30 \mathrm{~nm}$ for (ii) for the scale bar shown in (ii).

At neutral $\mathrm{pH}$, in a closed state, the pair components are in close proximity to each other, at which the donor emission is effectively quenched. By contrast, lowering the $\mathrm{pH}$ to 6 sharply increases the emission of rhodamine $\mathrm{G}(535 \mathrm{~nm})$, corresponding to the lid opening (Fig 1B, C). Further decreases in $\mathrm{pH}(<5.6)$ remove the lock strands, displaces the lid and open the box up (Fig S5C), which agrees with the disintegration observed by the electrophoretic analysis (Fig S5B). The results are characteristically consistent with the topography of the design, monitored by atomic force microscopy (AFM) ${ }^{37}$ In a pre-folded state, which lacks the lock strands, the topology appeared as a $\sim 60 \mathrm{~nm}$ sheet that was equal across all symmetry axes, while its thickness of $2 \mathrm{~nm}$ matched that of the DNA double helix (Fig 2). In a fully assembled, closed, state, monodisperse, discrete cubes of 20-25 nm in diameter were apparent (Figs 2 and S5D). In this assembled state the boxes remained stable in buffer under the experimental conditions of SEC and AFM imaging (Materials and Methods). Note should be taken that open origami designs tend to exhibit poor structural integrity in buffers containing low levels of divalent cations and therefore require protection (e.g. protein or peptide coating). ${ }^{38,39}$ Such protection also helps increase stability in diluted serum (e.g. $10 \%$ at $\left.37{ }^{\circ} \mathrm{C}\right) .{ }^{38}$ Encouragingly, when tested in $5 \%$ serum at $37{ }^{\circ} \mathrm{C}$ the designed boxes remained intact for several hours (Fig S5E). Collectively, the data confirms the physicochemical properties of the topology, as designed, prompting its functional assessment for intracellular protein delivery.

Designed with dimensions allowing for the encapsulation of several copies of the same protein, the box was co-assembled with a green fluorescent protein (GFP) into a closed state at protein/DNA (P/N) molar ratios of 750 (Fig 3A). The ratios were sufficient to demonstrate GFP encapsulation driven by diffusion (Fig S6A), with at least one in every ten boxes expected 
to encapsulate GFP. The protein has a suitable size $(4 \times 2.5 \mathrm{~nm})$ and appreciable intrinsic fluorescence, which facilitates in the monitoring of encapsulation by fluorescence. Following purification by size-exclusion chromatography (SEC) to remove excess protein and excess single strands (Fig S6B), fluorescent traces were recorded for boxes encapsulating GFP (Fig 3B).

A

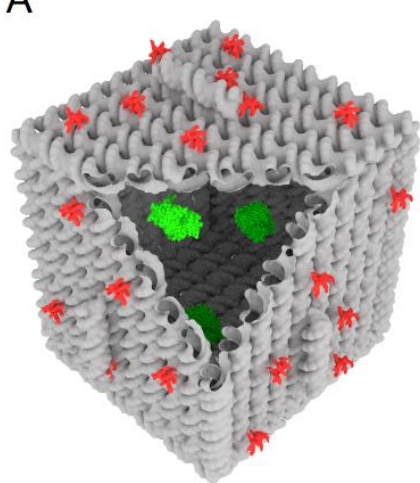

B

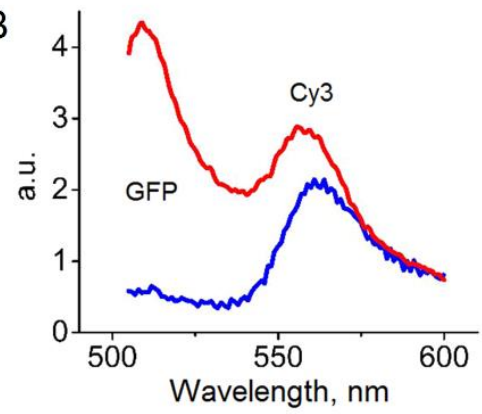

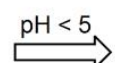

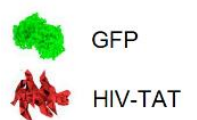

C

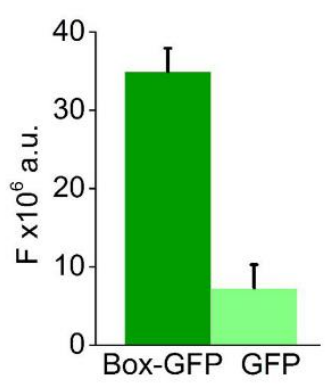

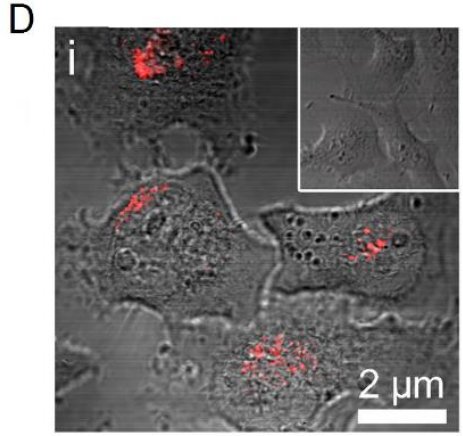

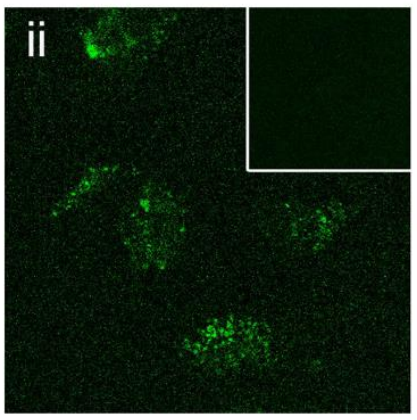

Figure 3. Biologically functional [3, 4]-fold DNA topology. (A) 3D molecular models of the functional assembly in a closed state (left) and in an opened-up state (right) showing the release of GFP. Note: the number of GFP molecules per DNA box is for illustration only. (B) Fluorescence traces of SEC-purified and Cy3-labelled boxes assembled with GFP. Closed and open states are shown in red and blue, respectively (C) Total fluorescence (GFP) of HeLa cells incubated with the functionalised boxes and GFP alone (control) after subtracting background fluorescence (untreated cells). Error bars denote standard deviations of three replicates each done in triplicate. (D) Combined bright field and fluorescence (Cy3) images (i) and corresponding fluorescence images (GFP) (ii) of HeLa cells incubated with the functionalised boxes after 6 hours of incubation. Inset images correspond to HeLa cells incubated with GFP complexed with HIV-Tat domains (control). 
Strong fluorescence was observed for both GFP $(515 \mathrm{~nm})$ and Cy3 $(550 \mathrm{~nm})$ for the boxes that were assembled with GFP and closed, i.e. GFP-loaded closed boxes (Fig S6C), with Cy3 being a complementary fluorescent dye incorporated into the boxes to enable differential fluorescence for cell imaging. The traces obtained for the GFP-loaded closed boxes were in drastic contrast to those obtained for boxes that remained open during incubation with GFP (Fig 3B). Indeed, no fluorescence was observed at $515 \mathrm{~nm}$, whereas Cy3 emission was comparable to that of the closed boxes (Fig 3B). This data supports the encapsulation of GFP, suggesting also that a more effective means could be used to reach high levels of protein packaging, e.g. via specific protein recognition motifs recruited in the interior of the boxes.

To render the topology infectious, the boxes were non-covalently decorated with HIV-Tat transduction domains (Fig 3A). ${ }^{40,41}$ As judged by dynamic light scattering measurements, at P/N (HIV-Tat to DNA) charge ratios of 1-6 the complexation led to marginal size increases without affecting the monodispersity of the assembly, with PDI values being typical of DNA origami, 0.2 (Fig S7A). No apparent aggregation was observed by AFM either (Fig S7B). Higher ratios gave no increase in complexation and no appreciable changes in the electrophoretic mobility of the boxes (Fig S7C), suggesting that complexation was complete at lower $\mathrm{P} / \mathrm{N}$ ratios. At the same lower ratios, as gauged by sigmoidal thermal denaturation curves, the assembly remained cooperative with a transition temperature of $56^{\circ} \mathrm{C}$, which in complex with the domains gave a net increase of over $4{ }^{\circ} \mathrm{C}$ in thermal stability (Fig S7D).

Boxes functionalized at the lower ratios effectively transfected HeLa cells promoting GFP release into the cytoplasm (Fig 3C, D). Particulate spreads of fluorescent DNA were apparent in the cytoplasm within the first hours of incubation suggesting an endocytic uptake (Fig S8 \& S9). The spreads were stable over 24 hours, so was the intracellular distribution of GFP (Fig 3C, D \& S10). No fluorescent traces could be detected for a Cy3-labelled non-assembling staple mixed with HIV-Tat and GFP (Fig 3C, D \& Fig S8-10). Quantitative flow cytometry 
and PCR measurements confirmed that HIV-Tat functionalized boxes effectively traversed cellular membranes and delivered GFP into the cytoplasm (Fig S11A-C), while transfection efficiencies appeared to improve at higher P/N ratios (Fig S11C).

To gain a better insight into the mechanistic uptake of the assembly, cells were incubated with $\mathrm{NH}_{4} \mathrm{Cl}$, that is commonly used to block endosomal acidification and escape. ${ }^{40}$ No apparent differences in median GFP fluorescence versus that of control cells $\left(\mathrm{NH}_{4} \mathrm{Cl}\right.$-untreated $)$ suggest that GFP-loaded HIV-Tat-functionalized boxes may remain trapped in endosomes or enter cells via a non-endocytic pathway (Fig S11E). To clarify this further, transfections were treated with bafilomycin A1 (Baf A1) - an antibiotic that arrests the endocytic uptake while inhibiting endosomal acidification. Baf A1 is a specific inhibitor of vacuolar ATPase proton pumps regulating sub-membranous $\mathrm{pH}$ and the formation of macropinosomes. ${ }^{42}$ The antibiotic caused up to $70 \%$ reductions in the uptake of the complex compared to the control incubations, indicating that endosomal uptake and escape were inhibited (Fig S11E). Together with the particulate spreads of fluorescent DNA and GFP observed by microscopy (Figs 3D, S8-S10) these results suggest that the designed topology favors an endocytic pathway to enter cells with likely a limited capacity to escape endosomes. Although the exact role of i-motif locks in the protein release is not completely clear, the mechanism of intracellular delivery is consistent with other DNA-origami topologies considered for drug delivery. ${ }^{43}$

\section{Conclusion}

In summary, we have introduced an everted-virus topology for functional protein delivery. The topology is assembled from a single-stranded virion DNA into a hollow cube with a [3, 4]-fold rotational symmetry. In contrast to the [3, 5]-fold topologies of viral capsids, which encase nucleic acids, this design encapsulates functional proteins and promotes their delivery into live cells, thus acting as an everted virus. To effectively infect cells, the cube is decorated with HIV- 
Tat transduction domains on its exterior and incorporates a closed lid which opens in acidified environments thereby responding to endosomal conditions. The topology exhibits a range of serum, thermal and structural stabilities which renders the design a promising platform for engineering bespoke non-polyhedral, non-protein synthetic viruses.

\section{Methods}

Materials. Native and modified DNA ( 0.1 or $1 \mu \mathrm{mol}$, desalted) were purchased from Integrated DNA Technologies (US). The modified DNA was purchased on a $1 \mu \mathrm{mol}$ scale with HPLC or PAGE purification. The scaffold strand M13mp18 was procured from New England Biolabs (UK). GFP was expressed from an eGFP plasmid and purified by size exclusion chromatography. The HIV-Tat peptide was prepared as described elsewhere. ${ }^{41}$ All other reagents and solvents were purchased from Sigma-Aldrich.

DNA design. The DNA origami was designed using CaDNAno software. ${ }^{19}$ It was generated using a square lattice framework, with M13mp18 as a scaffold strand. The sequences and 2D map are shown in Tables S1-S3, while the staple layout is given in Fig S1, S2. To insert the correct i-motif-forming sequence into the structure, the scaffold strand in the corresponding imotif region was formed from oligonucleotides separate from the M13mp18 scaffold (Table S2).

Folding DNA origami. To prepare DNA constructs, the M13mp18 scaffold strand (120 $\mu \mathrm{L}$, stock $100 \mathrm{nM}$, final concentration $12 \mathrm{nM})$ and a 10-fold excess of staple strands ( $150 \mu \mathrm{L}$, stock $390 \mathrm{nM}$, final concentration $58.5 \mathrm{nM}$ ), were added to PBS (10x) containing $140 \mathrm{mM} \mathrm{MgCl}_{2}$, pH 7.4 $(100 \mu \mathrm{L})$ and deionized water $(630 \mu \mathrm{L})$. DNA was folded by heating the solution to $70^{\circ} \mathrm{C}$ for $1 \mathrm{~min}$ and cooling to $5^{\circ} \mathrm{C}$ at a rate of $1^{\circ} \mathrm{C} / 15$ min using a PCR thermocycler. For FRET quenching studies, the rhodamine $G$ and Dabcyl staples were added to the reaction mixture to a final concentration of $0.4 \mu \mathrm{M}$, each. For Cy3 labelled studies, the Cy3 staple was added to the reaction mixture to a final concentration of 1.2 $\mu \mathrm{M}$. For GFP encapsulation studies, 
$300 \mu \mathrm{L}$ of deionised water was replaced for GFP $(300 \mu \mathrm{L}$, stock concentration $30 \mu \mathrm{M}$, final concentration of $9 \mu \mathrm{M}$, or stated otherwise). Note: the melting temperature of GFP is $>70^{\circ} \mathrm{C}$. To assemble the open box state, the two i-motif forming sequences in Table S2 were omitted from the folding mixture.

Size exclusion liquid chromatography. The assembled DNA origami box was purified from excess staple strands using an ÄKTA purifier 100/10 fitted with a Superdex 200 10/300 GL column (GE Healthcare) using PBS as an elution buffer. The sample was injected in a $1 \mathrm{~mL}$ volume to a $1 \mathrm{~mL}$ loading tube, with a flow rate of $0.5 \mathrm{~mL}$ per min at $8{ }^{\circ} \mathrm{C}$. The elution was monitored via UV-vis absorption at 260, 280, 488, 540 and $562 \mathrm{~nm}$, wherever appropriate, and collected in a 96 -well plate in $0.25 \mathrm{~mL}$ fractions. Fractions containing the folded DNA were pooled together, purified and the nanostructure was kept at $4^{\circ} \mathrm{C}$ and used within 24 hours.

DNA box concentration and the ratio to HIV-Tat. The concentration of the purified box was determined using a FLUOstar Omega plate reader equipped with LVis Plate in $\mu \mathrm{g} / \mathrm{mL}$. For cell studies, HIV-Tat domains (stock $0.15 \mathrm{mM}$ in Milli-Q water) were added in a 400-fold excess to the purified DNA box.

Agarose gel electrophoresis. The assembly products were analysed using a 1.5\% agarose gel electrophoresis in Tris-acetate-EDTA (TEA) buffer $(1 \mathrm{x})$. DNA samples $(10-20 \mu \mathrm{L})$ were mixed with an SDS-free gel (6 x) loading buffer $(5 \mu \mathrm{L}$, New England Biolabs) and loaded into the wells. The gels were run at $70 \mathrm{~V}$ for $1 \mathrm{~h}$ at $8^{\circ} \mathrm{C}$. A 1000-base-pair marker (New England Biolabs) was used as a reference standard, unless stated otherwise. DNA bands were visualized by ultraviolet after staining with ethidium bromide solution. For stability analysis in serum, the purified DNA box was incubated at $37{ }^{\circ} \mathrm{C}$ with $5 \%$ fetal bovine serum. $20 \mu \mathrm{L}$ samples were extracted at the time points stated, $5 \mu \mathrm{L}$ of gel loading dye was added and the solution was cooled on ice until the final time point was collected, after which all the fractions were analysed by agarose gel electrophoresis. For complexes with HIV-Tat, $20 \mu \mathrm{L}$ of the purified box was 
added to Tat $(0.1-2 \mu \mathrm{L})$ and equilibrated for $10 \mathrm{mins}$ at room temperature. After this, the gel loading dye $(5 \mu \mathrm{L})$ was added and the gel was performed.

Circular dichroism and ultraviolet spectroscopy. CD spectra were recorded on a Chirascan Plus spectropolarimeter (Applied Photophysics Ltd.) equipped with a Peltier temperature controller. All measurements were taken in millidegrees using a $1 \mathrm{~nm}$ step, $1 \mathrm{~nm}$ bandwidth, 0.5 second time/point, 2 acquisitions, and were recorded in a quartz cuvette with a $10 \mathrm{~mm}$ pathlength. The folding of staples forming i-motifs were monitored at $4.7 \mu \mathrm{M}$ (total $250 \mu \mathrm{L}$ in PBS, $1 \mathrm{x}$ ) containing $14 \mathrm{mM} \mathrm{MgCl}_{2}$ at $\mathrm{pH} 7.4$ and room temperature. $\mathrm{HCl}$ was added in $0.1 \mu \mathrm{L}$ fractions, and the $\mathrm{pH}$ was determined by a small-volume $\mathrm{pH}$ meter (Mettler Toledo).

Thermal denaturing studies were performed for the purified box encapsulating GFP (100 $\mu \mathrm{L}$, $19 \mu \mathrm{g}$ per $\mathrm{mL}$, abs $260 \mathrm{~nm}=0.38)$ without and with HIV-Tat $(0.8 \mu \mathrm{L}$, final concentration of 1.2 $\mu \mathrm{M})$. The sample was allowed to thermally equilibrate for 10 minutes at $20^{\circ} \mathrm{C}$ prior to heating from 20 to $80^{\circ} \mathrm{C}$. Absorbance was monitored at $260 \mathrm{~nm}$ at a scanning rate of $1^{\circ} \mathrm{C} / \mathrm{min}$, with the baseline subtracted.

Dynamic light scattering. DLS analysis was carried out on a Zetasizer Nano (ZEN3600, Malvern Instruments, UK) at $25^{\circ} \mathrm{C}$ using a $100 \mu \mathrm{L}$ disposable cuvette. The purified DNA box containing GFP $(100 \mu \mathrm{L}, 19 \mu \mathrm{g} / \mathrm{mL}$, abs $260 \mathrm{~nm}=0.38)$ was analyzed before and after the addition of HIV-Tat $(0.8 \mu \mathrm{L}$, final concentration of $1.2 \mu \mathrm{M})$. The sample was allowed to thermally equilibrate for 10 minutes at $25^{\circ} \mathrm{C}$, then scanned 7 times, each scan averaged and repeated 4 times. Hydrodynamic radii were obtained by fitting autocorrelation data to a single exponential function using the manufacture's Dispersion Technology Software (DTS version 5.10).

Fluorescence spectroscopy. A Varian Eclipse fluorescence spectrometer (Agilent, UK) was used to monitor the closed and opened states of the assembled box using a quartz cuvette with a path length of $1 \mathrm{~cm}$. Excitation at $505 \mathrm{~nm}(10 \mathrm{~mm}$ slit width $)$ and emission at $530 \mathrm{~nm}(5 \mathrm{~nm}$ slit width) were used with an average time/data point of 0.1 second, and a PMT voltage of 600 . 
Rhodamine $\mathrm{G}$ and dabcyl staple strands were used $(150 \mu \mathrm{L}, 17.5 \mu \mathrm{g}$ per $\mathrm{mL}$, abs $260 \mathrm{~nm}=0.35)$. $\mathrm{HCl}$ was added in $0.1 \mu \mathrm{L}$ fractions and the solution rapidly was mixed. $\mathrm{pH}$ was determined using a small volume $\mathrm{pH}$ meter in a separate control assay. To determine the presence of GFP inside the purified box labelled with Cy3 $(100 \mu \mathrm{L}, 19 \mu \mathrm{g} / \mathrm{mL}$, abs $260 \mathrm{~nm}=0.38)$, excitation was performed at $490 \mathrm{~nm}$ (GFP), and the emission scan range was 505-600 nm (Fig 3B).

Atomic force microscopy. DNA constructs $(0.5-10 \mu \mathrm{L}$, concentration 5-10 $\mathrm{nM})$ were incubated on a freshly cleaved mica disk for 20 minutes in TAE buffer with $14 \mathrm{mM} \mathrm{MgCl}_{2} \mathrm{pH}$ 7.4. After incubation, the substrate was washed $2 \mathrm{x}$ in buffer solution, and the volume increased to $\sim 50 \mu \mathrm{L}$ for imaging. Images were acquired at room temperature using a Multimode 8 Atomic Force Microscope (Bruker AXS, CA, USA) operated in PeakForce Tapping mode using PEAKFORCE-HIRS-F-B, and MSNL-E cantilever (Bruker AXS, CA, USA). Equivalent results were obtained with both cantilevers. Imaging was performed at a PeakForce frequency of $2 \mathrm{kHz}$, amplitude of $10 \mathrm{~nm}$ and a set-point of $10-40 \mathrm{mV}$, which corresponds to forces of $<100 \mathrm{pN} .{ }^{37}$ Images were acquired at line rates of $1 \mathrm{~Hz}$ with 512 pixels per line, for images of 0.2-1 $\mu \mathrm{m}$, resulting in a pixel size of 0.4-2 nm, and were processed using Nanoscope Analysis (Bruker AXS, CA, USA) for line-by-line flattening and removal of tilt using a first order polynomial.

Transfection assays. HeLa cells were maintained in DMEM cell culture medium supplemented with serum growth supplement and antibiotics (gentamicin and amphotericin B) in $25 \mathrm{~cm}^{2}$ culture flasks, and grown at $37{ }^{\circ} \mathrm{C}, 5 \% \mathrm{CO}_{2}$ for $24 \mathrm{~h}$ to reach $60 \%$ confluency. The cells were then washed $(\times 3)$ with PBS and trypsinized followed by the addition of trypsin inhibitors to eliminate secondary toxic effects of trypsin. Detached cells were spun down by centrifugation, and the excess solvent was replaced by cell growth media. $10 \mu \mathrm{L}$ of cell solution was mixed with $10 \mu \mathrm{L}$ of Trypan blue. The mixture was then placed on a counting plate to count cells. The purified box with Cy3 labelled DNA and encapsulated GFP (100 $\mu \mathrm{L}, 15 \mu \mathrm{g}$ 
per mL) was supplemented with HIV-Tat $(5 \mu \mathrm{L}$, final concentration $7.5 \mu \mathrm{M})$. For control assays, GFP $(100 \mu \mathrm{L}, 10 \mathrm{nM})$ was supplemented with HIV-Tat $(5 \mu \mathrm{L}$, final concentration 7.5 $\mu \mathrm{M})$, or $1 \mathrm{x}$ PBS containing $14 \mathrm{mM} \mathrm{MgCl}_{2}(100 \mu \mathrm{L})$. To the solution a $100 \mu \mathrm{L}$ of OptiMEMserum reduced media was added immediately before addition to cells. HeLa cells were seeded in an 8-well chamber (LabTek II chamber cover glass \#1.5 from Nalge Nunc (Roskilde, Denmark) at 10000 cells per well and incubated overnight at $37{ }^{\circ} \mathrm{C}, 5 \% \mathrm{CO}_{2}$. Before transfection, the cells were washed $(\times 3)$ with OptiMEM-Serum reduced media. The cells were incubated for $2 \mathrm{~h}$ at $37{ }^{\circ} \mathrm{C}$ in $100 \mu \mathrm{L}$ of the reagent. Images were acquired using a confocal laser scanning microscope (CLSM) (FV-1000, Olympus). Live cell imaging was performed under controlled environmental conditions with over 200 cells analysed per each time point in each experiment done in triplicate $\left(37^{\circ} \mathrm{C}, 5 \% \mathrm{CO}_{2}\right)$. Images were processed using Imaris v5.1 and ImageJ software. Quantitative PCR experiments for HIV-TaT-functionalised and bare boxes, following transfection, were performed as previously described elsewhere. ${ }^{12}$

Poisoned transfection. Growth media was removed from wells containing HeLa cells after overnight incubation allowing for cell attachment. $200 \mu \mathrm{L}$ Opti-MEM pre-incubated at $37^{\circ} \mathrm{C}$ containing either just Opti-MEM (control), $50 \mathrm{mM}$ ammonium chloride $\left(\mathrm{NH}_{4} \mathrm{Cl}\right)$ or $200 \mathrm{nM}$ bafilomycin A1 (Baf A1) were added to cells. These samples were further pre-incubated for 30 min at $37^{\circ} \mathrm{C}$ under $5 \% \mathrm{CO}_{2}$. After pre-incubation, HIV-Tat-functionalised GFP-loaded boxes were added to each well and incubated for $5 \mathrm{~h}$ at $37^{\circ} \mathrm{C}$ under $5 \% \mathrm{CO}_{2}$.

Flow Cytometry. Quantification of labelled intracellular uptake was performed by flow cytometry as previously described. ${ }^{12}$ Transfected cells were trypsinized and re-suspended in $200 \mu \mathrm{L}$ PBS. Fluorescence was measured by flow cytometry on a Cytek DxP8 FACScan (USA) and analysed using FlowJo software (USA). At least $10^{4}$ events were gated from each $\geq 10^{5}$ subset measured for each sample by forward scatter and side scatter ( $\mathrm{X}$ and $\mathrm{Y}$ axis, respectively) to extract and analyse $10^{4}$ single viable cells. From the untreated control cells, 
incubated with $200 \mu \mathrm{L}$ Opti-MEM containing no DNA, GFP or peptide, a negative population was taken as $0 \%$ negative. This gate was then used on all other samples to measure the relative population of negative (no fluorescence) and positive (fluorescence) cells, which was expressed in percentage.

\section{ASSOCIATED CONTENT}

\section{Supporting information}

Additional Tables and Figures as described in the text.

\section{AUTHOR INFORMATION}

\section{Corresponding author}

max.ryadnov@npl.co.uk

\section{Author Contributions}

JRB and MGR designed research. JRB, ALBP, BL and JEN performed research. MGR supervised research and wrote the manuscript. All authors analysed the data and edited the paper.

Notes

The authors declare no competing financial interests.

\section{ACKNOWLEDGEMENTS}

We acknowledge funding from the UK's Department for Business, Energy and Industrial Strategy; and from the UK's Engineering and Physical Sciences Research Council (EPSRC) in the form of an EPSRC fellowship to A. L. B. P (EP/M506448/1). We thank Kate Hammond and Georgina Benn for assistance with AFM imaging.

\section{REFERENCES}

(1) Perlmutter, J. D., and Hagan, M. F. (2015) Mechanisms of virus assembly. Annu. Rev Phys Chem, 66, 217-239. 
(2) Carrillo-Tripp, M., Shepherd, C. M., Borelli, I. A., Venkataraman, S., Lander, G., Natarajan, P., Johnson, J. E., Brooks, C. L., and Reddy, V. S. (2009) VIPERdb2: an enhanced and web API enabled relational database for structural virology. Nucleic Acids Res. 37, 436442.

(3) Mastrobattista, E., van der Aa, M. A., Hennink, W. E., and Crommelin, D. J. (2006) Artificial viruses: a nanotechnological approach to gene delivery. Nat Rev Drug Discov. 5, 115 121.

(4) Lamarre, B., and Ryadnov, M. G. (2011) Self-assembling viral mimetics: one long journey with short steps. Macromol. Biosci. 11, 503-513.

(5) Ni, R., and Chau, Y. (2014) Structural mimics of viruses through peptide/DNA coassembly. J Am. Chem. Soc. 136, 17902-17905.

(6) Nakai, T., Kanamori, T., Sando, S., and Aoyama, Y. (2003) Remarkably size-regulated cell invasion by artificial viruses. Saccharide-dependent self-aggregation of glycoviruses and its consequences in glycoviral gene delivery. J. Am. Chem. Soc. 125, 8465-8475.

(7) Maassen, S. J., van der Ham, A. M., and Cornelissen, J. L. M. (2016) Combining protein cages and polymers: from understanding self-assembly to functional materials. ACS Macro Lett. 5, 987-994.

(8) Matsuura, K. (2012) Construction of spherical virus-inspired peptide nanoassemblies. Polym. J. 44, 469-474.

(9) Matsuura, K., Watanabe, K., Matsuzaki, T., Sakuri, K., and Kimizuka, N. (2010) Selfassembled synthetic viral capsids from a 24-mer viral peptide fragment. Angew. Chem., Int. Ed. 49, 9662-9665.

(10) Hernandez-Garcia, A. et al. (2014) Design and self-assembly of simple coat proteins for artificial viruses. Nat Nanotechnol. 9, 698-702. 
(11) Bale, J. B., Gonen, S., Liu, Y., Sheffler, W., Ellis, D., Thomas, C., Cascio, D., Yeates, T. O., Gonen, T., King, N. P., and Baker, D. (2016) Accurate design of megadalton-scale twocomponent icosahedral protein complexes. Science 353, 389-394.

(12) Noble, J. E., De Santis, E., Ravi, J., Lamarre, B., Castelletto, V., Mantell, J., Ray, S., and Ryadnov, M. G. (2016) A de-novo virus-like topology for synthetic virions. J Am Chem. Soc. $138,12202-12210$.

(13) Castelletto, V., De Santis, E., Alkassem, H., Lamarre, B., Noble, J. E., Ray, S., Bella, A., Burns, J. R., Hoogenboom, B. W., and Ryadnov, M. G. (2016) Structurally plastic peptide capsules for synthetic antimicrobial viruses. Chem. Sci. 7, 1707-1711.

(14) Wörsdörfer, B., Woycechowsky, K. J., and Hilvert, D. (2011) Directed evolution of a protein container. Science 331, 589-592.

(15) Abbing, A. et al. (2004) Efficient intracellular delivery of a protein and a low molecular weight substance via recombinant polyomavirus-like particles. J Biol Chem. 279, 2741027421.

(16) Azuma, Y., Zschoche, R., Tinzl, M., and Hilvert, D. (2016) Quantitative packaging of active enzymes into a protein cage. Angew. Chem. Int. Ed. 55, 1531-1534.

(17) Yin, H., Kanasty, R. L., Eltoukhy, A. A., Vegas, A. J., Dorkin J. R., and Anderson, D. G. (2014) Non-viral vectors for gene-based therapy. Nat Rev Genetics 15, 541-555.

(18) Rothemund, P. W. (2006) Folding DNA to create nanoscale shapes and patterns. Nature 440, 297-302.

(19) Douglas, S. M., Marblestone, A. H., Teerapittayanon, S., Vazquez, A., Church, G. M., and Shih, W. M. (2009) Rapid prototyping of 3D DNA-origami shapes with caDNAno. Nucleic Acids Res. 37, 5001-5006. 
(20) Benson, E., Mohammed, A., Gardell, J., Masich. S., Czeizler, E., Orponen, P., and Högberg, B. (2015) DNA rendering of polyhedral meshes at the nanoscale. Nature 523, 441444.

(21) Chen, Y. J., Groves, B., Muscat, R. A., and Seelig, G. (2015) DNA nanotechnology from the test tube to the cell. Nat Nanotechnol. 10, 748-760.

(22) Ora, A., Järvihaavisto, E., Zhang, H., Auvinen, H., Santos, H. A., Kostiainen, M. A., and Linko, V. (2016) Cellular delivery of enzyme-loaded DNA origami. Chem. Commun. 52, 14161-14164.

(23) Schaffert, D. H., Okholm, A. H., Sørensen, R. S., Nielsen, J. S., Tørring, T., Rosen, C. B., Kodal, A. L., Mortensen, M. R., Gothelf, K. V., and Kjems, J. (2016) Intracellular delivery of a planar DNA origami structure by the transferrin-receptor internalization pathway. Small $12,2634-2640$.

(24) Shaw, A., Lundin, V., Petrova, E., Fördős, F., Benson, E., Al-Amin, A., Herland, A., Blokzijl, A., Högberg, B., and Teixeira, A. I. (2014) Spatial control of membrane receptor function using ligand nanocalipers. Nat Methods 11, 841-846.

(25) Zhao, Y. X., Shaw, A., Zeng, X., Benson, E., Nyström, A. M., and Högberg, B. (2012) DNA origami delivery system for cancer therapy with tunable release properties. ACS Nano 6, $8684-8691$.

(26) Mikkilä, J. et al. (2014) Virus-encapsulated DNA origami nanostructures for cellular delivery. Nano Lett. 14, 2196-2200.

(27) Perrault, S. D., and Shih, W. M. (2014) Virus-inspired membrane encapsulation of DNA nanostructures to achieve in vivo stability. ACS Nano 8, 5132-5140.

(28) Bhatia, D., Surana, S., Chakraborty, S., Koushika, S. P., and Krishnan, Y. (2011) A synthetic icosahedral DNA-based host-cargo complex for functional in vivo imaging. Nat Commun. 2, 339. 
(29) Chang, M., Yang, C.-S., and Huang, D.-M. (2011) Aptamer-conjugated DNA icosahedral nanoparticles as a carrier of doxorubicin for cancer therapy. ACS Nano 5, 61566163.

(30) Kohman, R. E., Cha, S. S., Man, H. Y., and Han X. (2016) Light-triggered release of bioactive molecules from DNA nanostructures. Nano Lett. 16, 2781-2785.

(31) Sprengel, A. et al. (2017) Tailored protein encapsulation into a DNA host using geometrically organized supramolecular interactions. Nat Commun. 8, 14472.

(32) Pan, K., Kim, D. N., Zhang, F., Adendorff, M. R., Yan, H., and Bathe, M. (2014) Lattice-free prediction of three-dimensional structure of programmed DNA assemblies. Nat Commun. 5, 5578.

(33) Andersen, E. S. et al. (2009) Self-assembly of a nanoscale DNA box with a controllable lid. Nature 459, 73-76.

(34) Douglas, S. M., Bachelet, I., and Church, G. M. (2012) A logic-gated nanorobot for targeted transport of molecular payloads. Science 335, 831-834.

(35) Gehring, K., Leroy, J. L., and Gueron, M. (1993) A tetrameric DNA structure with protonated cytosine-cytosine base pairs. Nature $363,561-565$.

(36) Liu, D., and Balasubramanian, S. (2003) A proton-fuelled DNA nanomachine. Angew. Chem. Inter. Ed. 42, 5734-5736.

(37) Pyne, A., Thompson, R., Leung, C., Roy, D., and Hoogenboom, B.W. (2014) Singlemolecule reconstruction of oligonucleotide secondary structure by atomic force microscopy. Small 10, 3257-3261.

(38) Ponnuswamy, N., Bastings, M. M. C., Nathwani, B., Ryu, J. H., Chou, L. Y. T., Vinther, M., Li, W. A., Anastassacos, F. M., Mooney, D. J., and Shih, W. M. (2017) Oligolysine-based coating protects DNA nanostructures from low-salt denaturation and nuclease degradation. Nat Commun. 8, 15654. 
(39) Auvinen, H. et al. Protein coating of DNA nanostructures for enhanced stability and immunocompatibility. (2017) Adv Healthc Mater. doi: 10.1002/adhm.201700692.

(40) Potocky, T. B., Menon, A. K., and Gellman, S. H. (2003) Cytoplasmic and nuclear delivery of a TAT-derived peptide and a beta-peptide after endocytic uptake into HeLa cells. $J$ Biol. Chem. 278, 50188-50194.

(41) Rakowska, P. D., Lamarre, B., and Ryadnov, M. G. (2014) Probing label-free intracellular quantification of free peptide by MALDI-ToF mass spectrometry. Methods, 68 , $331-337$.

(42) Koivusalo, M. et al. (2010) Amiloride inhibits macropinocytosis by lowering submembranous $\mathrm{pH}$ and preventing Rac1 and Cdc42 signaling. J. Cell Biol. 188, 547-563.

(43) Hu, Y., Chen, Z., Zhang, H., Li, M., Hou, Z., Luo, X., and Xue, X. (2017) Development of DNA tetrahedron-based drug delivery system. Drug Deliv. 24, 1295-1301. 